\title{
Cow's milk-specific T-cell reactivity of children with and without persistent cow's milk allergy: Key role for IL-10
}

\author{
Machteld M. Tiemessen, MSc, ${ }^{a}$ Adrie G. Van leperen-Van Dijk, BSc, ${ }^{a}$ \\ Carla A. F. M. Bruijnzeel-Koomen, PhD, MD, a Johan Garssen, PhD, ${ }^{b}$ \\ Edward F. Knol, PhD, ${ }^{a}$ and Els Van Hoffen, $\mathbf{P h D}^{\mathbf{a}}$ Utrecht and Wageningen, \\ The Netherlands
}

\begin{abstract}
Background: The role of antigen-specific $T$ cells in the mechanism of food allergy or maintenance of tolerance toward an innocuous antigen, such as cow's milk, is not yet fully understood.

Objective: The cow's milk-specific T-cell response of donors with various allergic backgrounds was investigated.

Methods: Cow's milk-specific T-cell clones (TCCs) were generated from the blood of children with persistent cow's milk allergy (CMA) and the blood of cow's milk-tolerant allergic and nonallergic control subjects. The TCCs were characterized by their antigen-specific proliferation, cytokine production, and activation status.

Results: Cow's milk-specific TCCs of children with persistent CMA were $T_{H} 2$ skewed, and the production of IL-4 and IL-13 was significantly correlated with the expression of the activation marker CD25. TCCs of the allergic control subjects were characterized by a high production of IL-10, which was positively correlated with the production of IL- 4 and IFN- $\gamma$ and with the expression of CD25. TCCs derived from nonallergic control subjects had an attenuated response toward cow's milk in that they did not produce high levels of cytokines nor did they express high levels of surface markers. As in the allergic control subjects, in the nonallergic control subjects IL-10 production was positively correlated with the expression of CD25. Conclusion: The activation status of $T$ cells derived from persistent donors with CMA was associated with the production of IL-4 and IL-13, whereas activated TCCs of cow's milktolerant control subjects were characterized by the production of IL-10 and, to a lesser extent, IFN- $\gamma$. These findings suggest that activated $\mathrm{CD}^{+} \mathrm{T}$ cells (characterized by a high $\mathrm{CD25}$ expression) might contribute to the tolerogenic immune response toward an antigen, such as cow's milk, through the production of IL-10. (J Allergy Clin Immunol 2004;113:932-9.)
\end{abstract}

Key words: Antigen-specific T cells, cow's milk, food allergy, tolerance, IL-10

Cow's milk allergy (CMA) is one of the most common food allergies in childhood and affects $2 \%$ to $2.5 \%$ of infants. ${ }^{1}$ The majority of infants with CMA outgrow their

From athe Department of Dermatology/Allergology, University Medical Center Utrecht, Utrecht, and ${ }^{\mathrm{b}}$ Numico Research, Wageningen.

Received for publication September 5, 2003; revised November 11, 2003; accepted for publication December 8, 2003.

Reprint requests: Machteld M. Tiemessen, MSc, Department of Dermatology/ Allergology (G02.124), University Medical Center, Utrecht, PO Box 85.500, 3508 GA Utrecht, The Netherlands. E-mail: e.vanhoffen@azu.nl $0091-6749 / \$ 30.00$

(C) 2004 American Academy of Allergy, Asthma and Immunology doi:10.1016/j.jaci.2003.12.016
Abbreviations used

AC: Allergic control subjects with a diagnosed food allergy other than CMA

CMA: Cow's milk allergy

CMP: Cow's milk protein

EBV-B cells: EBV-transformed B cells

NAC: Nonallergic control subjects

TCC: T-cell clone

TCR: T-cell receptor

allergy before their third year of life, whereas a small percentage $(15 \%)$ of this population has persistent allergy to cow's milk. ${ }^{2}$ The question remains why some children outgrow their CMA and others do not. Comparison of the cow's milk-specific T-cell response between patients with persistent or transient CMA, patients with other food allergies, and nonallergic individuals might provide more insight into the regulation of the immune response toward cow's milk.

Cow's milk contains several allergenic proteins. The most important allergens are 4 caseins ( $\alpha$ s 1, $\alpha$ s $2, \beta$, and $\kappa)$ and 2 whey proteins ( $\alpha$-lactalbumin and $\beta$-lactoglobulin). Recent studies have demonstrated that the persistency of CMA is associated with differences in IgE-binding epitopes to the different cow's milk proteins (CMPs). ${ }^{3,4}$ Because $\mathrm{T}$ cells are responsible for the isotype switching of antigen-specific B cells to IgE, T-cell activation is the initial step in determination of the outcome of the immune response and plays a major role in the maintenance of the reaction. This might suggest that the observed differences in IgE-binding epitopes could be reflected in the CMPspecific T-cell pool. However, T-cell reactivity of patients with a persistent CMA has not been investigated.

Considering the low frequency of allergen-specific $\mathrm{T}$ cells in peripheral blood, it is difficult to investigate the functional role of these $\mathrm{T}$ cells in the pathogenesis of allergy. ${ }^{5}$ Studies have been performed with PBMCs in which allergen-specific proliferation and, to a minor extent, cytokine production could be measured. ${ }^{6,7}$ Cloning of antigen-specific $\mathrm{T}$ cells has been proved to be a powerful tool to investigate the immune response to allergens at the T-cell level. ${ }^{8-10}$

Previous results by our group have demonstrated that CMP-specific T cells isolated from infants with transient CMA display a $\mathrm{T}_{\mathrm{H}}$ 2-skewed phenotype, with high levels 
of IL-4, IL-5, and IL-13. ${ }^{11}$ This finding was similar to those of other studies that demonstrated that allergen-specific $\mathrm{T}$ cells from donors with food allergy are committed to a $\mathrm{T}_{\mathrm{H}} 2$ phenotype. ${ }^{8,12}$ How tolerance toward food antigens is achieved or maintained by nonallergic individuals is not yet fully known. Several studies have suggested that $T_{H} 1$ responses to food antigens underlie the immunologic mechanism of a nonallergic state and resolution of food allergies. $^{11,13-15}$ However, recent publications indicate that in the regulation of the immune response, during induction and maintenance of tolerance, the production of immunosuppressive cytokines, such as IL-10, TGF- $\beta$, or both, also play a crucial role. ${ }^{16-18}$ More insight into the allergen-specific T-cell responses of donors with different allergic backgrounds might shed some light on the natural state of tolerance toward the allergen or the absence thereof.

In this study 3 patient groups were investigated for their T-cell responses at the clonal level toward cow's milk. One group consisted of highly allergic children with persistent CMA (CMA group), one control group consisted of highly allergic children with a diagnosed food allergy other than CMA (AC), and one group contained nonallergic control subjects (NAC). T-cell clones (TCCs) were generated from peripheral blood in an antigenspecific manner and cultured to determine antigen-specific proliferation, cytokine production, and expression of cellsurface markers.

\section{METHODS}

\section{Patients}

Five patients with CMA (age range, 6-14 years; mean age, 9.6 years), 4 patients without CMA (age range, 4.8-9.6 years; mean age, 7.2 years), and 4 nonallergic control subjects (age range, 6.9-10.2 years; mean age, 8.3 years) were included in the study. After informed consent was obtained, a venous blood sample was taken. CMA was diagnosed on the basis of positive cow's milk-specific serum IgE levels, a positive skin prick test response, and a positive double-blind, placebo-controlled food challenge result with cow's milk. In short, the double-blind, placebo-controlled food challenge was performed with 2 randomized challenge formulas. The CMP-containing formula was composed of a series of 6 doses of CMP increasing from $0.2 \mathrm{~g}$ to $1.6 \mathrm{~g}$ hidden in an extensively hydrolyzed formula. The placebo formula consisted of 6 doses of the same extensively hydrolyzed formula. The doses of each formula series were given at 30-minute time intervals. The control subjects without CMA (ACs) had a diagnosed food allergy other than for cow's milk (positive IgE level, positive skin prick test response, and convincing clinical history or positive open challenge result for peanut, hen's egg, or both), no history of CMA, and severe atopic dermatitis. The nonallergic control subjects (NACs) had no increased serum IgE levels and no clinical history of atopy (Table I). The study was approved by the Medical Ethical Committee of the University Medical Center, Utrecht.

\section{Preparation of cow's milk-specific TCCs}

Cow's milk-specific TCCs were generated as described previously. ${ }^{11,19}$ The antigen used for T-cell stimulation was a mix of CMPs, which consisted of equal quantities of total casein, $\alpha-$ lactalbumin, and $\beta$-lactoglobulin $(50 \mu \mathrm{g} / \mathrm{mL}$ each; gift from Dr R. Floris, NIZO food research, Ede, The Netherlands). In short, PBMCs were cultured with CMPs during the first 14 days and thereafter restimulated with irradiated autologous EBV-transformed B cells (EBV-B cells) preincubated overnight with CMPs as antigenpresenting cells. If these cultures indicated a high CMP-specific Tcell proliferation on the lymphocyte stimulation test, $\mathrm{T}$ cells were cloned by limiting dilution. Established TCCs were tested by means of lymphocyte stimulation testing to determine specificity for the various CMPs and were restimulated every 14 days.

\section{Cell culture media}

EBV-B cells were cultured in RPMI-1640 (Gibco, NY) supplemented with $10 \%$ FCS. Established TCCs were maintained in Iscove modified Dulbecco medium (Gibco) supplemented with 2\% pooled human $\mathrm{AB}$ serum, $5 \%$ Yssel medium, ${ }^{20}$ and $50 \mathrm{U} / \mathrm{mL}$ IL-2 and IL-4 (a kind gift from Novartis Research Institute, Vienna, Austria). For the experiments performed to test antigen specificity, cytokine production, and expression of cell-surface markers, IL-2 and IL-4 were omitted from the medium. All media were supplemented with penicillin (100 IU/mL), streptomycin $(100 \mathrm{mg} / \mathrm{mL})$, and glutamine (1 mmol/L; Gibco).

\section{CMP-specific cytokine release}

To determine CMP-specific cytokine release, $10^{6}$ cells of each TCC were incubated with $10^{6}$ irradiated autologous EBV-B cells that had been preincubated overnight with CMPs. Control cultures of TCCs and EBV-B cells preincubated without antigen were prepared in parallel. Stimulation was performed in a 24-well plate at a final volume of $1 \mathrm{~mL}$. After 24 hours of culture, supernatants were collected and stored at $-20^{\circ} \mathrm{C}$. Cytokines were measured by means of ELISA, according to the manufacturer's recommendations (IL-4, IL10, IL-13, and IFN- $\gamma$; Sanquin, Amsterdam, The Netherlands). The detection limit was $0.6 \mathrm{pg} / \mathrm{mL}$ for IL-4, $1.2 \mathrm{pg} / \mathrm{mL}$ for IL-10, $2 \mathrm{pg} / \mathrm{mL}$ for IFN- $\gamma$, and $0.5 \mathrm{pg} / \mathrm{mL}$ for IL-13.

\section{Flow cytometry}

Expression of cell-surface markers was investigated 48 hours after CMP-specific stimulation. The following antibodies were used: FITC-conjugated CD4, anti-T-cell receptor (TCR) $\alpha \beta$, and phycoerythrin-conjugated CD8, CD69, and CD25 (all obtained from BD Biosciences, San Jose, Calif). Expression levels of the markers by each TCC were measured as mean fluorescence intensity. Analysis was performed on a Becton Dickinson FACScan with WinMDI software.

\section{Statistical analysis}

Nonparametric analysis (Mann-Whitney $U$ test) was applied to determine significant differences between the cell-surface markers of the TCCs of the different patient groups. Before the analysis of the cytokine data, all cytokine results were first normalized by ${ }^{10} \mathrm{log}$ transformation, and differences between the cytokine profiles of the TCCs of the 3 patient groups were analyzed by using a Student $t$ test. Correlations between the production of the different cytokines were calculated with the parametric Pearson test, and the correlation between the expression of CD25 and the different cytokine productions was calculated with the nonparametric Spearman rho method. Differences associated with $P$ values of less than .05 were considered significant.

\section{RESULTS \\ Antigen specificities of $T$ cells derived from different patient groups}

Cow's milk-specific TCCs isolated from peripheral blood display various antigen specificities. The TCCs of the CMA group versus the TCCs of the AC and NAC groups do not show a preference for a specific CMP

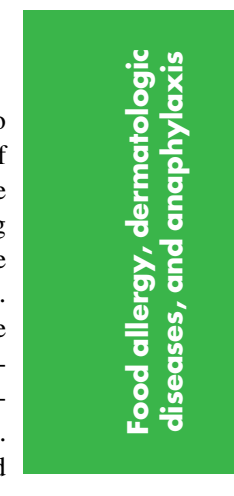


TABLE I. Characteristics of the included patients

\begin{tabular}{lrccc}
\hline $\begin{array}{l}\text { Patient } \\
\text { group and } \\
\text { patient no. }\end{array}$ & $\begin{array}{c}\text { Total } \\
\text { IgE } \\
\text { (kU/L) }\end{array}$ & $\begin{array}{c}\text { CMP- } \\
\text { specific } \\
\text { IgE (kU/L) }\end{array}$ & $\begin{array}{c}\text { CMP- } \\
\text { specific } \\
\text { skin prick test }\end{array}$ & DBPCFC \\
\hline CMA & & & & \\
1 & 2630 & 44 & $3+$ & Positive \\
2 & 327 & 3 & $3+$ & Positive \\
4 & 1081 & 11.6 & $4+$ & Positive \\
5 & 1022 & 9.2 & + & Positive \\
14 & 131 & 3.8 & ND & \\
AC & & & - & \\
11 & 515 & $<0.35$ & - & \\
12 & 852 & $<0.35$ & & \\
17 & 333 & $<0.35$ & & \\
18 & 728 & 0.6 & & \\
NAC & & & & \\
8 & 85 & Negative & & \\
9 & 5 & Negative & & \\
15 & Negative & Negative & & \\
16 & Negative & Negative & & \\
\hline
\end{tabular}

$D B P C F C$, Double-blind, placebo-controlled food challenge; $N D$, not done.

(Table II). In all groups a diverse repertoire of TCCs could be generated to most of the different CMPs. The proliferative capacity of the TCCs was not significantly different (data not shown).

\section{CMP-specific cytokine production}

The CMP-specific cytokine production was measured 24 hours after stimulation to examine $\mathrm{T}$-cell reactivity of $\mathrm{T}$ cells derived from the patient groups. The production of the $\mathrm{T}_{\mathrm{H}} 2$ cytokines IL-4 and IL-13 in response to CMP stimulation was significantly higher in TCCs derived from children with CMA compared with TCCs derived from children in the AC and NAC groups (Fig 1, $A$ and $B$ ). The CMP-specific IL-4 production was significantly higher in TCCs derived from the AC group compared with TCCs obtained from the NAC group, which was not seen for the CMP-specific IL-13 production. The production of IFN- $\gamma$ was higher in TCCs from both children with CMA and the AC group relative to the TCCs of the NAC group (Fig 1, $C)$. Interestingly, the CMP-specific IL-10 production was significantly higher in TCCs derived from children in the AC group compared with TCCs derived from both children with CMA and children in the NAC group (Fig 1,D).

\section{Correlation between production of cytokines}

Correlations between the production of IL-10 and the production of IL-4, IL-13, and IFN- $\gamma$ were examined to obtain more information on the high IL-10-producing $\mathrm{T}$ cells found in the AC group. No correlation between the production of IL-10 and IL-4 was observed in the CMA group, and a negative correlation was found with the production of IFN- $\gamma(r=-0.256, P<.05$, Fig 2$)$. A trend toward a negative correlation was found with regard to the production of IL-10 and IL-13 in the TCCs of the CMA group $(r=-0.205, P=.070$, data not shown). A positive correlation between the production of both IL-10 and IL-4 and of IL-10 and IFN- $\gamma$ in the TCCs of the AC group was
TABLE II. Specificities of the TCCs of the 3 patient groups

\begin{tabular}{|c|c|c|c|c|c|c|c|c|}
\hline \multirow{2}{*}{$\begin{array}{l}\text { Patient } \\
\text { group }\end{array}$} & \multicolumn{5}{|c|}{ Casein } & \multirow{2}{*}{$\begin{array}{l}\alpha- \\
\text { Lactalbumin }\end{array}$} & \multirow{2}{*}{$\begin{array}{l}\beta- \\
\text { Lactoglobulin }\end{array}$} & \multirow{2}{*}{$\begin{array}{l}\text { No. of } \\
\text { TCCs }\end{array}$} \\
\hline & $\alpha s 1$ & $\alpha s 2$ & $\boldsymbol{\beta}$ & $\kappa$ & NS & & & \\
\hline CMA & 5 & 5 & 3 & 35 & 8 & 20 & 3 & 79 \\
\hline $\mathrm{AC}$ & 46 & 1 & 0 & 24 & 0 & 4 & 13 & 85 \\
\hline NAC & 48 & 1 & 4 & 27 & 1 & 1 & 1 & 83 \\
\hline
\end{tabular}

NS, Specific for total casein but not for one of the casein subfractions.

found ( $r=0.678$ and $r=0.808$, respectively; $P<.01$; Fig 2 ), but no correlation between the production of IL-10 and IL-13 was found (not shown). Similar to the positive correlation between the production of IL-10 and IFN- $\gamma$ found in the TCCs of the AC group, a positive correlation was also demonstrated with the TCCs obtained from the NAC group $(r=0.398, P<.01)$. No correlation was found between the production of IL-10 and the $\mathrm{T}_{\mathrm{H}} 2$ cytokines IL-4 (Fig 2) and IL-13 (not shown) in the NAC group.

\section{Expression of cell-surface markers after CMP-specific stimulation}

All TCCs generated from the different donors were found to be $\mathrm{CD}^{+}{ }^{+} \mathrm{T}_{\mathrm{H}}$ cells. T cells isolated from children with persistent CMA expressed an activation pattern that was determined by a high expression of the $\alpha \beta$ TCR and of the activation marker CD69. The expression of CD69 and of the $\alpha \beta$ TCR was significantly increased in the TCCs from the children with CMA compared with TCCs from the NAC group and for CD69 also compared with that seen in the AC group (Fig 3). The expression level of CD25 in the TCCs from the CMA group was comparable with the expression level of CD25 in the TCCs from the AC group and significantly higher compared with the TCCs of the NAC group (Fig 3). T cells isolated from children in the NAC group displayed low expression of all measured surface markers.

\section{Correlation of the expression level of CD25 with the production of IL-4, IL-13, IL-10, and IFN- $\gamma$}

Despite the lack of difference between the expression levels of CD25 on T cells of the AC group versus those of the CMA group, a clear difference was found between the correlation of the expression level of CD25 and the production of IL-4, IL-13, IL-10, and IFN- $\gamma$. The production of IL-4 and IL-13 by TCCs of the CMA group was positively correlated with the expression of CD25 on these $\mathrm{T}$ cells $(r=0.239$ and $r=0.278$, respectively; $P<.05$; Fig 4, A). No correlation could be found between the IL-4 and IL-13 production and CD25 expression in the T cells of both control groups. A positive correlation was found between the CD25 expression and the amount of IFN- $\gamma$ produced in the AC group $(r=0.248, P<.05)$ but not in the CMA group. Interestingly, a high expression level of CD25 in T cells derived from both control groups was associated with high levels of IL-10 ( $r=0.388$, $P<.01$ and $r=0.453, P<.01$, respectively), whereas no 

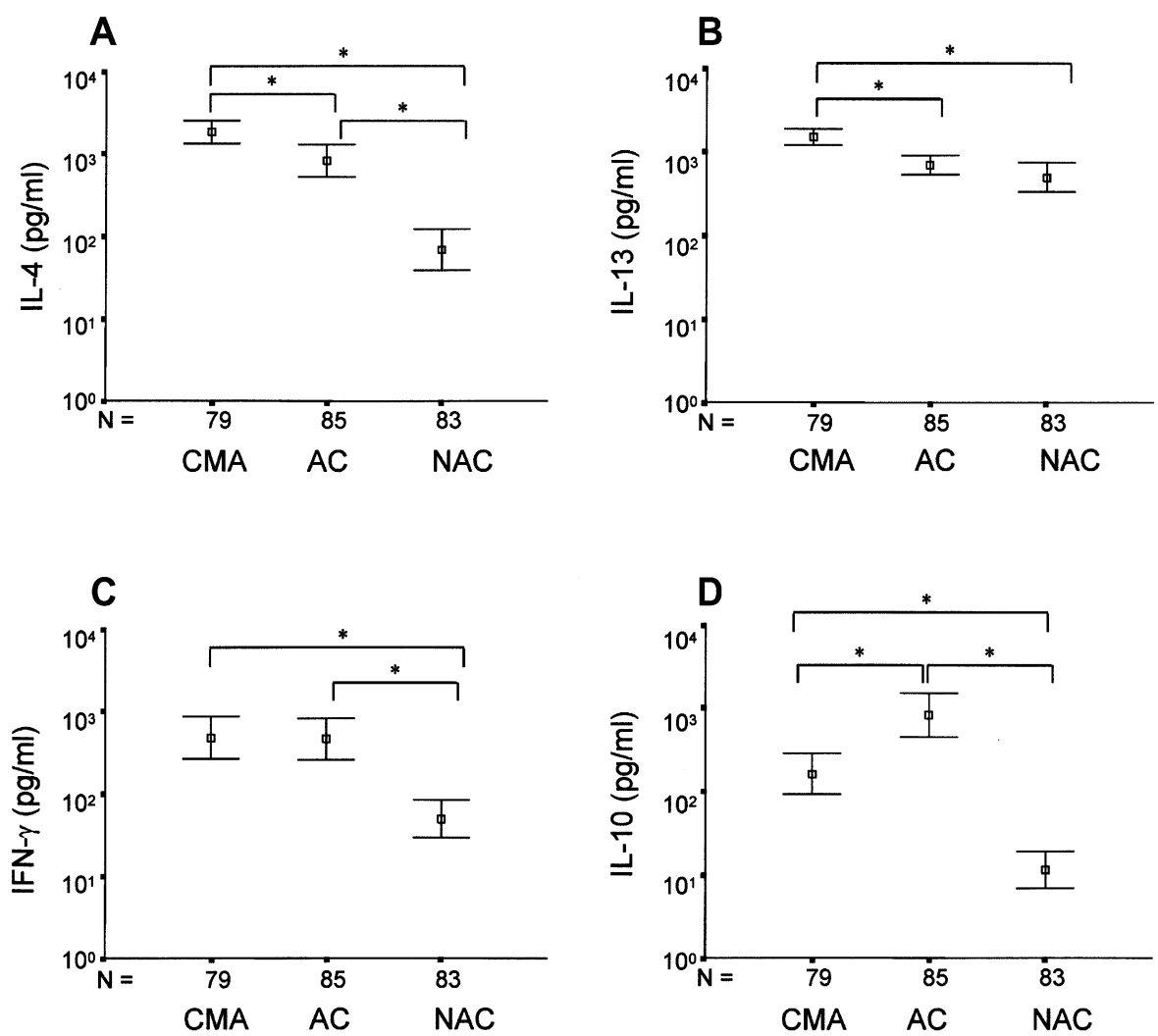

FIG 1. Cytosine production of TCCs derived from 3 patient groups. TCCs from 3 different groups (CMA $[n=79], A C$ [ $=85]$, and NAC [ $=83$ ] groups) were assessed for their CMP-specific cytokine production. The amount of IL-4 (A), IL-13 (B), IFN- $\gamma$ (C), and IL-10 (D) was measured in culture supernatants. The results are expressed as $95 \% \mathrm{Cls}$ for each group. Statistical analysis was performed with a Student $t$ test, and significant differences between the groups are indicated in the graphs $\left({ }^{*} P<.01\right)$.

correlation was observed in the T cells from the CMA group (Fig 4, B).

\section{DISCUSSION}

CMA in infants is usually transient and disappears with aging. However, for a subgroup of children, CMA is persistent. Whether this lack in tolerance development toward cow's milk is a result of CMP-specific T cells that are not able to switch their cytokine profile or that are not efficiently controlled by suppressor cells has not been elucidated yet. The characteristics of the CMP-specific T-cell population of donors with different allergic backgrounds might contribute to the understanding of how some food antigens are tolerated. For this purpose, CMP-specific TCCs were generated from peripheral blood and analyzed for their antigen specificity, cytokine production, and expression of surface markers in a CMPspecific manner. The use of CMP-specific TCCs enabled us to investigate the T-cell response toward CMPs at the individual T-cell level without the interference of other cell populations.

The findings in this study show that CMP-specific T cells derived from children with persistent CMA are characterized by a significantly increased production of the $\mathrm{T}_{\mathrm{H}} 2$ cytokines IL- 4 and IL-13, as was already demonstrated by our group for infants with transient CMA. ${ }^{11,19}$ In contrast, the CMP-specific production of IFN- $\gamma$, which was low in transient allergic infants compared with atopic control subjects, ${ }^{11}$ was comparable between the CMA and the AC groups in this study. This might suggest that a high production of IFN- $\gamma$ is associated with persistent CMA. In children with persistent hen's egg allergy, it was also shown that the production of IFN- $\gamma$ relative to the production of $\mathrm{T}_{\mathrm{H}} 2$ cytokines was higher than in younger infants with hen's egg allergy. However, the same cytokine pattern was found in children who had outgrown their allergy. ${ }^{17}$ These data, together with the observed high IFN- $\gamma$ production of the $\mathrm{T}$ cells from the CMA group in this study, suggest that although a high production of IFN- $\gamma$ might be associated with a persistent food allergy, this is not sufficient to induce tolerance in these children. CMP-specific IL-10 production was significantly enhanced in the TCCs derived from the AC group compared with the TCCs derived from the CMA and NAC groups. These data suggest that CMP-specific T cells from the AC group, with no history of CMA, create a tolerogenic microenvironment through the production of IL-10. The production of IL-10 by the CMP-specific T 
CMA
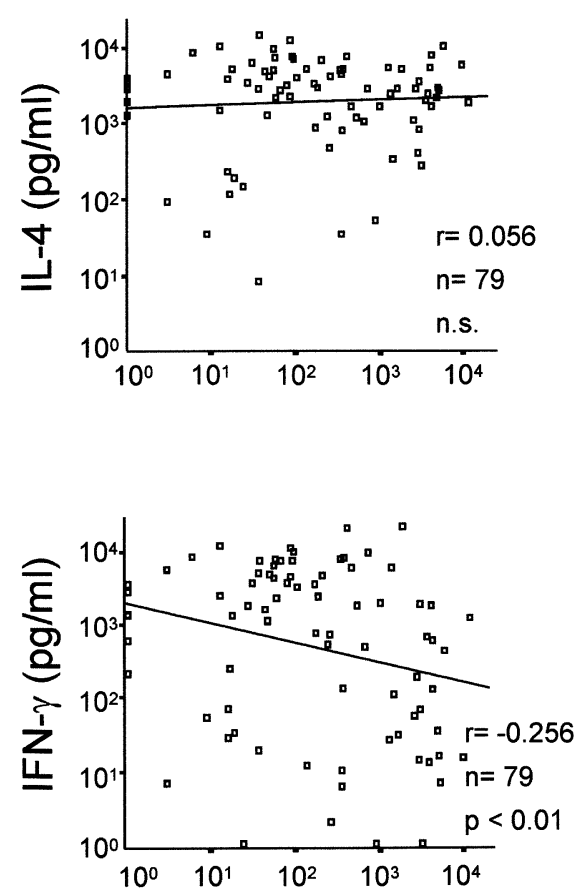

$A C$

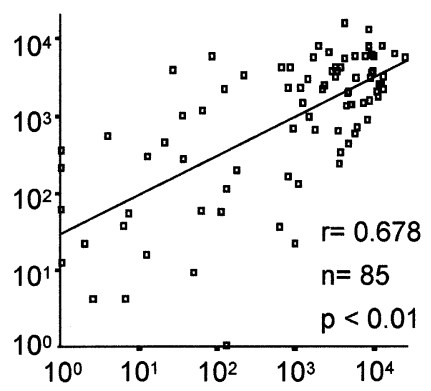

NAC

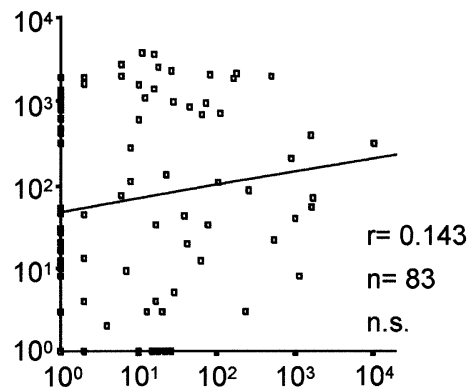

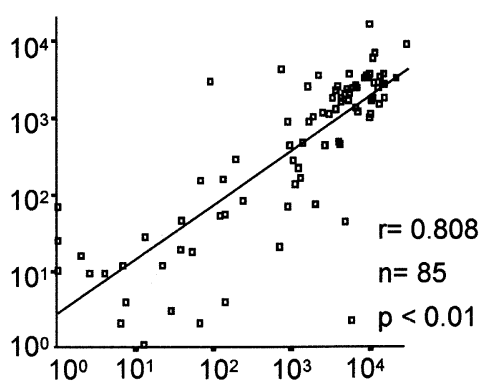

IL-10 (pg/ml)

FIG 2. Correlation between CMP-specific IL- 4 and IFN- $\gamma$ production and IL-10 production. CMP-specific IL-4 and IFN- $\gamma$ production of the TCCs of the 3 groups (CMA, AC, and NAC) was correlated to CMP-specific IL-10 production by using the Pearson test.

cells of the AC group might be the mechanism through which the development of an adverse reaction to CMPs is prevented in these children. Because the AC group is clinically allergic to many other allergens except cow's milk, their T-cell repertoire to these allergens is probably highly $\mathrm{T}_{\mathrm{H}} 2$ skewed. Although not allergic to cow's milk, these patients do have a tendency of $\mathrm{a}_{\mathrm{H}} 2$ skewing toward cow's milk, as is supported by the relatively high amount of IL-4 produced by these T cells compared with those of the NAC group. However, this relatively high IL-4 production correlates positively with the IL-10 production, suggesting that IL-10 compensates for the partial overshoot in the IL-4 production, thereby preventing the development of an allergic response to this particular antigen. Interestingly, the IL-10 production in the CMA and NAC groups is not positively correlated with the IL-4 production, indicating that the high IL-4 production of T cells in the CMA group is not balanced by a high IL-10 production, whereas the IL-4 production of T cells in the NAC group is very low and might not need the counterbalance of IL-10. At the other side of the $T_{H} 1 / T_{H} 2$ spectrum, the CMP-specific IL-10 production appeared to correlate positively with IFN- $\gamma$ production in both the $\mathrm{AC}$ and NAC groups and negatively in the CMA group. This suggests that CMP-specific IFN- $\gamma$ production is counterbalanced by IL-10 in both control groups and not in the CMA group, which therefore might contribute to the allergic status of the children in the CMA group. Recently, it was described in a mouse model of allergic asthma that the development of oral tolerance is associated with the production of IL-10 by antigen-specific $\mathrm{CD}^{+}{ }^{+} \mathrm{T}_{\text {cells. }}{ }^{21}$ The phenomenon of IL-10-producing $\mathrm{T}$ cells ameliorating atopic disorders was already found in several other models of tolerance induction, such as immunotherapy. $^{22,23}$ Moreover, it has been shown in both mice and human subjects that parasite-induced levels of IL-10 are protective toward the development of atopy. ${ }^{24,25}$ These data indicate an important role for IL-10-producing T cells in the process of tolerance. TGF- $\beta$ has been shown to be able to induce IL-10 production in T cells. ${ }^{26}$ Recently, it has been described that the amount of TGF- $\beta$-producing $\mathrm{T}$ cells in the duodenal mucosa was decreased in children with food allergy. ${ }^{27}$ Therefore one might speculate that the observed reduced production of TGF- $\beta$ in food allergy might lead to insufficient induction of tolerance, resulting in reduced production of IL-10 in children with CMA, as shown in our study.

A clear characteristic for the TCCs obtained from the children with a persistent form of CMA is the high expression of the early activation marker CD69 at 48 hours after CMP stimulation. This might indicate that CMP-specific $\mathrm{T}$ cells from children with CMA remain activated for a longer period, whereas CMP-specific T cells of both control groups rapidly return to a resting 

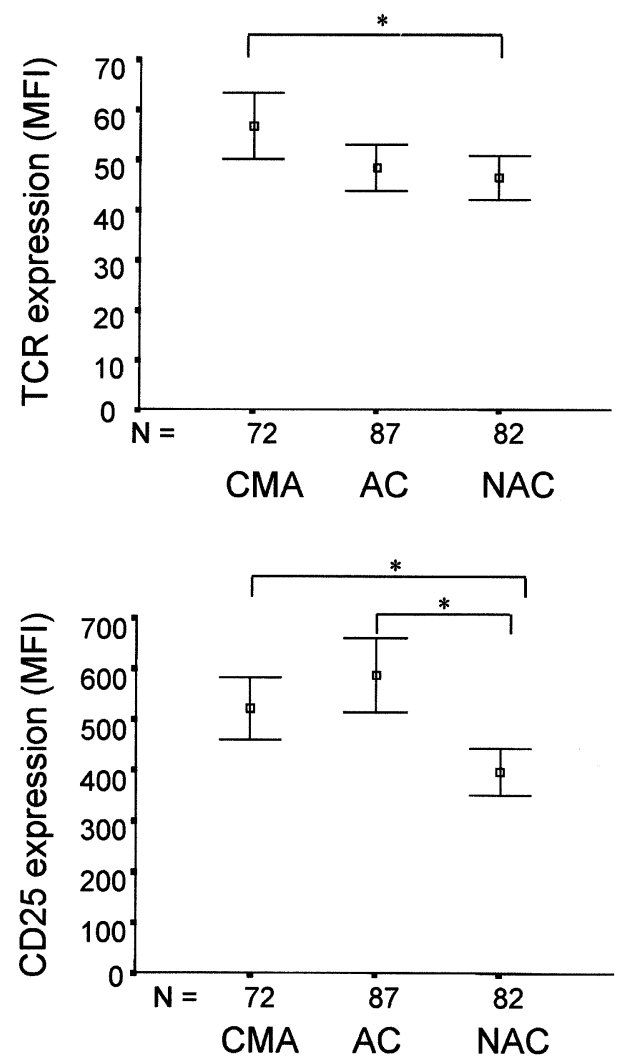

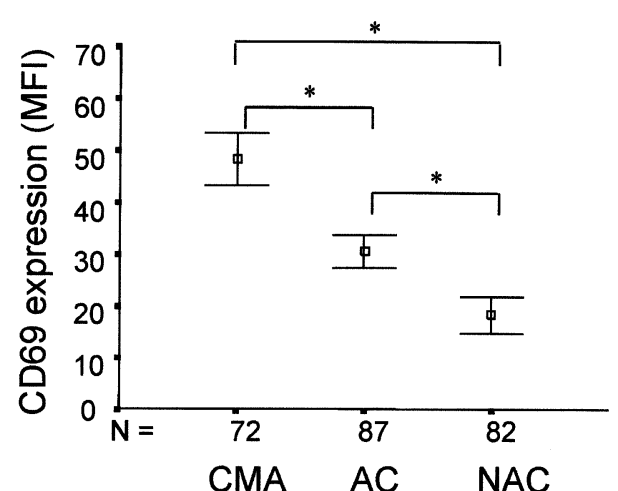

FIG 3. Differences in the expression level of the $\alpha \beta$ TCR, CD69, and CD2 5 in TCCs derived from the 3 donor groups. The expression level of the $\alpha \beta$ TCR, CD69, and CD25 was measured by using flow cytometry. The $95 \% \mathrm{Cl}$ of the mean fluorescence intensity for all TCCs obtained in the 3 groups is shown for the 3 parameters. Analysis was performed with a nonparametric Mann-Whitney $U$ test, and significant differences are shown in the graphs $\left({ }^{*} P<.05\right)$.

state. The CMP-specific TCCs of the NAC group have a significantly lower expression of CD69 and the TCR compared with the CMA and AC groups, indicating their attenuated activation state in response to CMPs. The percentage of $\mathrm{CD} 9^{+} \mathrm{T}$ cells has been found to be increased in individuals with an IgE-mediated adverse drug reaction. ${ }^{28}$ The latter observation, as well as the high expression of CD69 in the TCCs of the CMA group, indicates the involvement of $\mathrm{CD} 9^{+} \mathrm{T}$ cells in the allergic reaction in allergic individuals.

We previously demonstrated that a high CD25 expression was a characteristic of the CMP-specific $\mathrm{T}$ cells derived from infants with transient CMA. ${ }^{19}$ In the current study the CD25 expression of CMP-specific $\mathrm{T}$ cells from children with persistent CMA was high compared with that in the NAC group but was not different from the expression found in the AC group. The high $\mathrm{CD} 25$ expression in the $\mathrm{AC}$ group in the present study is probably associated with the highly atopic background of the subjects. All children in the AC group had multiple allergies (food and inhalant) and severe atopic dermatitis, implying a highly triggered immune system. In contrast, the atopic control subjects in the study of Schade et al ${ }^{19}$ had only a mild form of atopic dermatitis. The TCCs from the NAC group have a significantly lower expression of CD25 compared with those of the children with persistent CMA (Fig 3), which confirms the previous observations in nonatopic infants compared with infants with transient CMA. $^{19}$

Although we could not demonstrate a difference in the expression of CD25 between the AC and CMA groups in this study, a clear difference was found between the correlation of the produced cytokines and the expression level of CD25. A positive correlation between the expression of CD25 and the production of IL-4 and IL-13 was demonstrated in the CMA group, whereas this correlation was absent in both control groups. Interestingly, in asthmatic lung tissue a positive correlation was found between IL-5 mRNA expression and the number of $\mathrm{CD} 25^{+}$cells. ${ }^{29}$ We found a positive correlation between the expression of CD25 and both IFN- $\gamma$ and IL-10 in the AC group and between CD25 and IL-10 in the NAC group. These results indicate that activation of $\mathrm{T}$ cells of the 3 groups is associated with different cytokine profiles and is thereby able to mediate different immune responses. It has been shown that IL-10 is underexpressed in the lungs of asthmatic individuals compared with that seen in healthy control subjects, indicating a role for IL-10 in the 


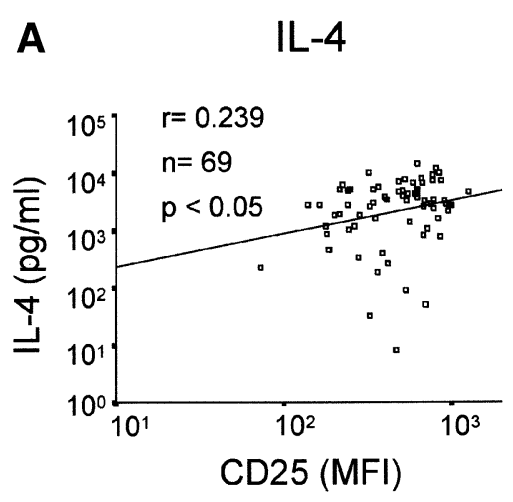

B

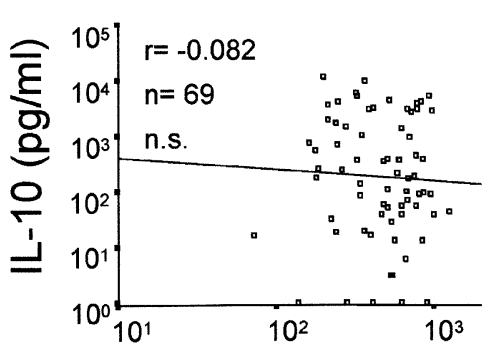

IL-13

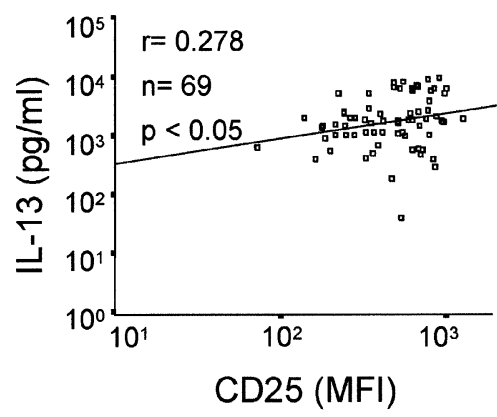

AC

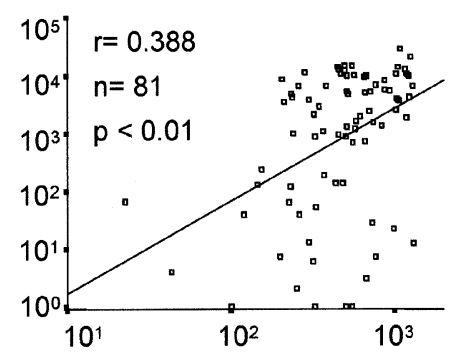

NAC

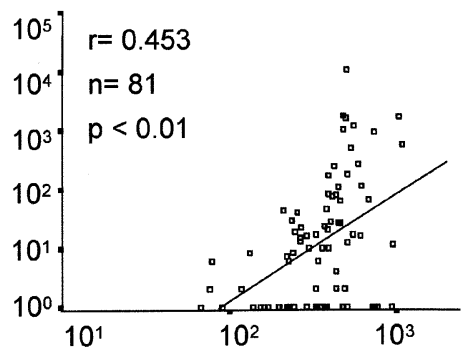

\section{CD25 (MFI)}

FIG 4. Correlation between CD25 expression and cytokine production. A, Correlation between the expression level of CD25 and the production of IL-4 and IL-13 is shown per TCC for the CMA group. B, Correlation between the expression level of CD25 and the production of IL-10 is shown per TCC for the 3 groups (CMA, $A C$, and NAC). Spearman rho correlations are indicated in the graphs.

prevention of allergic disorders. ${ }^{30}$ The latter observation, together with the presented data, support the idea of an active form of tolerance induction in the $\mathrm{AC}$ group mediated through the production of at least IL-10 and, to a minor extent, IFN- $\gamma$.

The data presented in this report demonstrate that $\mathrm{T}$-cell reactivity, assessed at the clonal level by means of flow cytometry and cytokine production, can be a powerful tool in the attempt to elucidate the mechanism by which the different patient groups tolerate or do not tolerate a harmless food antigen, such as cow's milk. It was shown that activation (CD25 expression) of allergenspecific $\mathrm{T}$ cells is associated with a high production of IL-4 and IL-13 in children with persistent CMA and with a high production of IL-10 and, to a lesser extent, IFN$\gamma$ in cow's milk-tolerant children. These data suggest that activated allergen-specific $\mathrm{T}$ cells might contribute to an active form of immunosuppression in vivo through the production of IL-10 and thereby prevent aberrant reactions toward innocuous antigens, such as cow's milk.

We thank R. Floris, PhD (NIZO food research, Ede, The Netherlands), for the purified CMPs; the Bloodbank Utrecht for providing us with human $\mathrm{AB}$ serum; Rogier Schade, MD, $\mathrm{PhD}$, for help with the inclusion of the patients; and Leonie Taams, $\mathrm{PhD}$, for critical reading of the manuscript.

\section{REFERENCES}

1. Sampson HA. Food allergy. Part 1: immunopathogenesis and clinical disorders. J Allergy Clin Immunol 1999;103:717-28.

2. Sicherer SH, Sampson HA. Cow's milk protein-specific IgE concentrations in two age groups of milk-allergic children and in children achieving clinical tolerance. Clin Exp Allergy 1999;29:507-12.

3. Vila L, Beyer K, Jarvinen KM, Chatchatee P, Bardina L, Sampson HA. Role of conformational and linear epitopes in the achievement of tolerance in cow's milk allergy. Clin Exp Allergy 2001;31: 1599-606.

4. Jarvinen KM, Beyer K, Vila L, Chatchatee P, Busse PJ, Sampson HA. B-cell epitopes as a screening instrument for persistent cow's milk allergy. J Allergy Clin Immunol 2002;110:293-7.

5. Neumann C, Gutgesell C, Fliegert F, Bonifer R, Herrmann F. Comparative analysis of the frequency of house dust mite specific and nonspecific Th1 and Th2 cells in skin lesions and peripheral blood of patients with atopic dermatitis. J Mol Med 1996;74:401-6.

6. Lagging E, Hage-Hamsten M, Gronneberg R, Elfman L, Harfast B. Cytosine production in PBMC from allergics and non-allergics following in vitro allergen stimulation. Immunol Lett 1998;60:45-9.

7. Werfel T, Ahlers G, Schmidt P, Boeker M, Kapp A. Detection of a kappacasein-specific lymphocyte response in milk-responsive atopic dermatitis. Clin Exp Allergy 1996;26:1380-6.

8. de Jong EC, Spanhaak S, Martens BP, Kapsenberg ML, Penninks AH, Wierenga EA. Food allergen (peanut)-specific TH2 clones generated from the peripheral blood of a patient with peanut allergy. J Allergy Clin Immunol 1996;98:73-81.

9. Higgins JA, Lamb JR, Lake RA, O'Hehir RE. Polyclonal and clonal analysis of human CD4+ T-lymphocyte responses to nut extracts. Immunology 1995;84:91-7. 
10. Gurka G, Ohman J Jr, Rosenwasser LJ. Allergen-specific human T cell clones: derivation, specificity, and activation requirements. J Allergy Clin Immunol 1989;83:945-54

11. Schade RP, Ieperen-Van Dijk AG, Van Reijsen FC, Versluis C, Kimpen $\mathrm{JL}$, Knol EF, et al. Differences in antigen-specific T-cell responses between infants with atopic dermatitis with and without cow's milk allergy: relevance of TH2 cytokines. J Allergy Clin Immunol 2000;106: 1155-62.

12. Katsuki T, Shimojo N, Honma K, Tsunoo H, Kohno Y, Niimi H Establishment and characterization of ovalbumin-specific $\mathrm{T}$ cell lines from patients with egg allergy. Int Arch Allergy Immunol 1996;109: 344-51.

13. Turcanu V, Maleki SJ, Lack G. Characterization of lymphocyte responses to peanuts in normal children, peanut-allergic children, and allergic children who acquired tolerance to peanuts. J Clin Invest 2003; 111:1065-72.

14. Nagata S, McKenzie C, Pender SL, Bajaj-Elliott M, Fairclough PD, Walker-Smith JA, et al. Human Peyer's patch T cells are sensitized to dietary antigen and display a Th cell type 1 cytokine profile. J Immunol 2000; 165:5315-21.

15. Schade RP, Tiemessen MM, Knol EF, Bruijnzeel-Koomen CA, Van Hoffen E. The cow's milk protein-specific T cell response in infancy and childhood. Clin Exp Allergy 2003;33:725-30.

16. Zemann B, Schwaerzler C, Griot-Wenk M, Nefzger M, Mayer P, Schneider $\mathrm{H}$, et al. Oral administration of specific antigens to allergyprone infant dogs induces IL-10 and TGF-beta expression and prevents allergy in adult life. J Allergy Clin Immunol 2003;111:1069-75.

17. Ng TW, Holt PG, Prescott SL. Cellular immune responses to ovalbu$\mathrm{min}$ and house dust mite in egg-allergic children. Allergy 2002;57: 207-14.

18. Jutel M, Akdis M, Budak F, Aebischer-Casaulta C, Wrzyszcz M, Blaser $\mathrm{K}$, et al. IL-10 and TGF-beta cooperate in the regulatory $\mathrm{T}$ cell response to mucosa allergens in normal immunity and specific immunotherapy. Eur J Immunol 2003;33:1205-14.

19. Schade RP, Ieperen-Van Dijk AG, Versluis C, Van Reijsen FC, Kimpen JL, Bruijnzeel-Koomen CA, et al. Cell-surface expression of CD25, CD26, and CD30 by allergen-specific $\mathrm{T}$ cells is intrinsically different in cow's milk allergy. J Allergy Clin Immunol 2002;109: 357-62.
20. Yssel H, de Vries JE, Koken M, Van Blitterswijk W, Spits H. Serum-free medium for generation and propagation of functional human cytotoxic and helper T cell clones. J Immunol Methods 1984;72:219-27.

21. Smart V, Foster PS, Rothenberg ME, Higgins TJ, Hogan SP. A plantbased allergy vaccine suppresses experimental asthma via an IFNgamma and CD4+CD45RBlow T cell-dependent mechanism. J Immunol 2003;171:2116-26.

22. Oh JW, Seroogy CM, Meyer EH, Akbari O, Berry G, Fathman CG, et al. CD4 T-helper cells engineered to produce IL-10 prevent allergeninduced airway hyperreactivity and inflammation. J Allergy Clin Immunol 2002; 110:460-8

23. Akdis CA, Blesken T, Akdis M, Wuthrich B, Blaser K. Role of interleukin 10 in specific immunotherapy. J Clin Invest 1998;102:98-106.

24. van den Biggelaar AH, van Ree R, Rodrigues LC, Lell B, Deelder AM, Kremsner PG, et al. Decreased atopy in children infected with Schistosoma haematobium: a role for parasite-induced interleukin-10. Lancet 2000;356:1723-7.

25. Bashir ME, Andersen P, Fuss IJ, Shi HN, Nagler-Anderson C. An enteric helminth infection protects against an allergic response to dietary antigen. J Immunol 2002;169:3284-92.

26. Kitani A, Fuss I, Nakamura K, Kumaki F, Usui T, Strober W. Transforming growth factor (TGF)- $\{$ beta $\} 1$-producing regulatory $\mathrm{T}$ cells induce Smad-mediated interleukin 10 secretion that facilitates coordinated immunoregulatory activity and amelioration of TGF- $\{$ beta $\} 1-$ mediated fibrosis. J Exp Med 2003;198:1179-88.

27. Perez-Machado MA, Ashwood P, Thomson MA, Latcham F, Sim R, Walker-Smith JA, et al. Reduced transforming growth factor-beta1producing $\mathrm{T}$ cells in the duodenal mucosa of children with food allergy. Eur J Immunol 2003;33:2307-15.

28. Torres MJ, Corzo JL, Leyva L, Mayorga C, Garcia-Martin FJ, Antunez $\mathrm{C}$, et al. Differences in the immunological responses in drug- and virusinduced cutaneous reactions in children. Blood Cells Mol Dis 2003;30: 124-31.

29. Hamid Q, Azzawi M, Ying S, Moqbel R, Wardlaw AJ, Corrigan CJ, et al. Expression of mRNA for interleukin-5 in mucosal bronchial biopsies from asthma. J Clin Invest 1991;87:1541-6.

30. Borish L, Aarons A, Rumbyrt J, Cvietusa P, Negri J, Wenzel S. Interleukin-10 regulation in normal subjects and patients with asthma. J Allergy Clin Immunol 1996;97:1288-96. 